\title{
Coherence of "Open" Initiatives in Higher Education and Research: Framing a Policy Agenda
}

\author{
Sheila Corrall ${ }^{1}$, Stephen Pinfield ${ }^{2}$ \\ ${ }^{1}$ University of Pittsburgh \\ ${ }^{2}$ University of Sheffield
}

\begin{abstract}
"Open" approaches have the potential to advance significantly the mission of higher education and research institutions worldwide, but the multiplicity of initiatives raises questions about their coherence and points to the need for a more coordinated approach to policy development. Drawing on the European e-InfraNet project, we adopt a broad definition of Open, including activity alongside content, and identify the different Open domains, their salient characteristics and relationships. We propose a high-level typology and model of Open to inform policy design and delivery, and employ Willinsky's framework for open source and open access to discuss the theoretical underpinnings of openness, finding important commonalities among the domains, which suggests that the framework can extend to all the Open areas. We then examine potential shared benefits of Open approaches, which reinforce the argument for a unified policy agenda. We conclude with some observations on limits of openness, and implications for policy.

Keywords: academic culture; educational policy; open science; research infrastructure; scholarly communication

Citation: Corrall, S., \& Pinfield, S. (2014). Coherence of "Open" Initiatives in Higher Education and Research: Framing a Policy Agenda. In iConference 2014 Proceedings (pp. 293-313). doi:10.9776/14085

Copyright: Copyright is held by the authors.

Acknowledgements: The authors would like to thank Lilian van der Vaart, lead author of the e-InfraNet project final report, for her contributions to an earlier discussion document that informed this paper. Thanks also to the other contributors to the e-Infranet project for their work which was an important influence on this paper. Stephen Pinfield was a contributing author to the e-Infranet report.

Contact: scorrall@pitt.edu, s.pinfield@sheffield.ac.uk
\end{abstract}

\section{Introduction}

The "Open" agenda is assuming growing importance in the higher education and research (HER) community worldwide. Approaches such as providing open access (OA) to research publications, sharing open data, releasing open educational resources (OER), and developing open-source software (OSS) are becoming widespread. There are both bottom-up pressures, from researchers, librarians, educationalists, and technologists creating open systems and making content openly available; and top-down forces, with policymakers and research funders encouraging or even mandating open approaches (Andersen, 2010; Kelly, Wilson, and Metcalfe, 2007; Kuchma, 2008; Pinfield, 2012; Schuwer \& Mulder, 2009; Stokker, 2011).

Openness is "a trend, both in terms of the production and sharing of educational materials, as well as making research publications (and even research data) freely available" (Conole \& Alevizou, 2010, p. 42). Described as "two broad movements" (open research and open education), digital scholarship is crucially influenced by the convergence of social constructivism and Web 2.0 technologies in the late 20th and early 21st centuries (Esposito, 2013), but has historical roots as far back as the "open science" ethos of the late 16th and early 17th centuries (David, 2004). The "Open" agenda is accordingly extending apace into all areas and activities of the academy, impacting its core missions of teaching and research, as well as the systems and processes that are critical to individual and institutional success. It is becoming a guiding principle of HER in the modern world.

However, as observed by the educational philosopher, Michael Peters (2010, p. 80), openness is "a complex code word for a variety of digital trends and movements...based on the growing and overlapping complexities of open source, open access, open archiving, open publishing and open science" and has "deeper registers that refer more widely to government ('open government'), society ('open society'), economy ('open economy') and even psychology (openness as one of the five traits of personality theory)." The multifarious open movements are at different stages of evolution and maturity, and the nature of the concept and the culture of the academy and its hinterland mean that there are continuing debates and disputes around what openness means in particular domains irrespective of their age and development.

Moreover, despite obvious connections between different open activities at a conceptual level, these initiatives have typically been pursued within specialist communities without coordination. The 
related policy and practitioner literature is similarly disparate, although it shows increasing convergence between OER and OSS in the learning and teaching context (Andersen, 2010; Christiansen \& Anderson, 2004; Conole \& Alevizou, 2010; liyoshi \& Kumar, 2008; Leeson \& Mason, 2007; Wiley \& Gurrell, 2009), and between OSS and open science in the research arena (Lyon, 2009; Rhoten \& Powell, 2007; Royal Society, 2012; Schroeder, 2007; Whyte \& Pryor, 2011; Willinsky, 2005). Some commentators have used the Boyer (1997, pp. 24-25) model of scholarship lately to advance a more integrated view of openness, showing how digital practices are transforming all four of his categories of academic work: research/discovery, synthesis/integration, practice/application, and teaching (Garnett \& Ecclesfield, 2011; Katz, 2010; Pearce, Weller, Scanlon, \& Ashleigh, 2010). Recently, Wellen (2013) has examined the commonalities between OA to research outputs and MOOCs (Massive Open Online Courses) from a political economy perspective, arguing in particular that the "unbundling" of previously integrated processes and roles in their production create the conditions for "disruptive" change.

Peters and Roberts $(2012$, p. 4) are notable examples of the few scholars to investigate at a deeper, philosophical level the historical and contemporary connections between the diverse concepts of openness, specifically:

"the social processes and policies that foster openness as an overriding educational and scientific value, evidenced in the growth of open source, open access, open education, and their convergences that characterize global knowledge communities."

Another significant contribution, but at the policy level, is the work of the European Network for Co-ordination of Policies and Programmes on e-Infrastructure (e-InfraNet, 2013), which has scoped a broad policy framework for open approaches in HER in the context of European Union initiatives on innovation and digital agenda. Informed by European projects and developments, supplemented by evidence from global sources, e-InfraNet $(2012,2013)$ provides an overview and synthesis of different types of open activity and their relationships, and a compelling argument for openness as "the default modus operandi for research and higher education."

Within this context, our purpose here is to map out the current Open landscape from a policy development perspective, considering in particular the potential for greater coordination between different Open approaches. We first identify the main characteristics of the various Open domains, deploying a broad definition of "Open" to capture the present range of Open initiatives. We next advance and elaborate a high-level typology of Open to inform policy development, and discuss whether the different Open initiatives can be approached in a coordinated way as part of a single coherent policy agenda. We suggest that a framework put forward by Willinsky (2005) for understanding the convergence of open source, $\mathrm{OA}$, and open science can extend to other Open domains. We then outline the potential shared benefits of the different Open approaches, which we argue strengthen the case for convergence, while also commenting on some limits of openness, and we conclude with our observations on the policy implications of our findings.

\section{Definitions and Dimensions of Openness}

Defining "open" clearly and unambiguously is important from a policy-development as well as a conceptual perspective. Different interpretations of the concept can result in different outcomes in practice and protracted debates among stakeholders, notable instances being text mining of journal articles, where only some versions of OA permit harvesting and analysis of content, (Clark, 2013; Howard, 2012; McDonald \& Kelly, 2012) and open standards in the IT industry, where there are competing visions of openness and how it applies to the products and processes of standards development (ANSI, 2005; Cerri \& Fuggetta, 2007; Tiemann, 2005). Varying interpretations of what "open" means are especially common when the particular phenomenon is at an emergent stage, exemplified by the different approaches to open peer review reported in the literature (Ford, 2013; Shotton, 2012; Ware, 2011).

The various arenas of open activity have generated a range of definitions. The open access (OA) movement, in particular, has several widely cited definitions of the basic concept and salient dimensions that are potentially applicable to other open areas. The seminal Budapest Open Access Initiative (BOAI, 2002) limits its scope to peer-reviewed journal literature (including unreviewed pre-prints) and defines the concept thus:

“...free availability on the public internet, permitting any users to read, download, copy, distribute, print, search, or link to the full texts of these articles, crawl them for indexing, pass them as data to software, or use them for any other lawful purpose, without financial, legal, or technical barriers other than those inseparable from gaining access to the internet itself. The only constraint on 
reproduction and distribution, and the only role for copyright in this domain, should be to give authors control over the integrity of their work and the right to be properly acknowledged and cited."

This early characterization significantly incorporates the ability to both view content and reuse it in various ways. Suber $(2012$, pp. 65,66$)$ disambiguates these issues using terminology from the software community to define two "sub-species of OA":

"Gratis $O A$ is free of charge... Users must still seek permission to exceed fair use. Gratis OA removes price barriers but not permission barriers."

"Libre OA is free of charge and also free of some copyright and licensing restrictions ... Libre OA removes price barriers and at least some permission barriers."

Libre OA has recently proved controversial, generating extensive policy-based debate. Some publishers allow free viewing of content, but not various kinds of reuse without permission, significantly limiting the practical benefits of OA. Text mining often involves copying, reformatting, and analyzing large corpora of textual material, which contravenes the licenses of many publishers, even if they allow some kind of Gratis openness. Policymakers thus cannot assume that requiring authors to make outputs Open will necessarily allow content to be mined (or be used in other ways); so, when formulating policy, they need to consider carefully the level of openness required on the Gratis-Libre spectrum to ensure the intended practical outcome.

Taking the perspective of an educationalist looking at open educational resources (OER), Wiley (2010, p. 16) also emphasizes the importance of user permissions in relation to open content, describing "4 Rs" of Open:

- Reuse: the right to reuse the content in its unaltered/verbatim form (e.g., make a backup copy of the content)

- Revise: the right to adapt, adjust, modify, or alter the content itself (e.g., translate the content into another language)

- Remix: the right to combine the original or revised content with other content to create something new (e.g., incorporate the content into a mashup)

- Redistribute: the right to share copies of the original content, the revisions, or the remixes with others (e.g., give a copy of the content to a friend)"

Wiley (2010) defines "reuse" narrowly, but his other "Rs" encompass a broad set of secondary-use activities, presented here as an essential feature of Open in the context of OER. Other formal definitions, including the Open Knowledge Foundation (OKF, 2011) Open Definition Project, also emphasize minimal restrictions on various sorts of reuse, reworking and redistribution.

Such definitions assume openness applies specifically to content, rather than more generally for example, to activity. In contrast, some definitions from the IT and software community emphasize process-based openness. For example, Weber (2004, p. 56) states,

"The essence of open source is not the software. It is the process by which software is created. Think of the software itself as an artifact of the production process. And artifacts are often not the appropriate focus of a broader explanation."

Understanding the process of OSS creation, sometimes known as "open development" (Anderson, 2009) to distinguish it from OSS as product, is important in grasping the full potential of Open in different contexts. The discourse on open standards similarly emphasizes development in an open process (Ray, Gulla, Dash, \& Gupta, 2011) and although definitions here exhibit varying levels of openness, they are typically multi-dimensional, for example:

"Open standards are developed in a transparent and collaborative process, are available for free or at a nominal cost and can be implemented royalty free - in particular regarding software interoperability standards - or at reasonable cost." (Undheim \& Friedrich, 2008, p. 2)

Table 1 illustrates the range of open phenomena found in academic discourse and practice, showing how the balance, granularity, and interplay of product and process are manifested in different domains. 


\begin{tabular}{|c|c|c|}
\hline Concept & Definition & Source \\
\hline $\begin{array}{l}\text { Open } \\
\text { bibliography }\end{array}$ & $\begin{array}{l}\text { "systematic efforts to create and maintain stores of Openly } \\
\text { accessible, machine-readable bibliographic data" }\end{array}$ & $\begin{array}{l}\text { Jones et al. } \\
(2011)\end{array}$ \\
\hline Open content & $\begin{array}{l}\text { "...a collective name for creative work published under a non- } \\
\text { restrictive licence that explicitly permits the work to be copied and } \\
\text { - depending on the particular licence chosen - to also be adapted } \\
\text { and distributed." }\end{array}$ & $\begin{array}{l}\text { Keller \& } \\
\text { Mossink }(2008 \\
\text { p. } 13)\end{array}$ \\
\hline $\begin{array}{l}\text { Open } \\
\text { courseware } \\
(\mathrm{OCW})\end{array}$ & $\begin{array}{l}\text { "free and open digital publication of high quality college and } \\
\text { university-level educational materials. ...organized as courses, } \\
\text { and often include course planning materials and evaluation tools } \\
\text { as well as thematic content. ...openly licensed, accessible to } \\
\text { anyone, anytime via the internet." }\end{array}$ & $\begin{array}{l}\text { OCW } \\
\text { Consortium } \\
\text { [n.d.] }\end{array}$ \\
\hline Open data & $\begin{array}{l}\text { "Data that meets the criteria of intelligent openness. Data must be } \\
\text { accessible, usable, assessable and intelligible." }\end{array}$ & $\begin{array}{l}\text { Royal Society } \\
(2012 \text {, p. 12) }\end{array}$ \\
\hline $\begin{array}{l}\text { Open } \\
\text { development }\end{array}$ & $\begin{array}{l}\text { "the community-led development model found within many } \\
\text { successful free and open source software projects." }\end{array}$ & $\begin{array}{l}\text { Anderson } \\
(2009)\end{array}$ \\
\hline $\begin{array}{l}\text { Open educational } \\
\text { practices (OEP) }\end{array}$ & $\begin{array}{l}\text { "...collaborative practice in which resources are shared by making } \\
\text { them openly available, and pedagogical practices are employed } \\
\text { which rely on social interaction, knowledge creation, peer- } \\
\text { learning, and shared learning practices." }\end{array}$ & $\begin{array}{l}\text { Ehlers }(2011, p \text {. } \\
6)\end{array}$ \\
\hline $\begin{array}{l}\text { Open educational } \\
\text { resources (OER) }\end{array}$ & $\begin{array}{l}\text { "...teaching, learning and research materials in any medium, } \\
\text { digital or otherwise, that reside in the public domain or have been } \\
\text { released under an open license that permits no-cost access, use, } \\
\text { adaptation and redistribution by others with no or limited } \\
\text { restrictions." }\end{array}$ & $\begin{array}{l}\text { UNESCO } \\
(2012, \text { p. } 1)\end{array}$ \\
\hline $\begin{array}{l}\text { Open innovation } \\
\text { (OI) }\end{array}$ & $\begin{array}{l}\text { "the use of purposive inflows and outflows of knowledge to } \\
\text { accelerate internal innovation, and expand the markets for } \\
\text { external use of innovation, respectively. ...assumes that firms can } \\
\text { and should use external ideas as well as internal ideas, and } \\
\text { internal and external paths to market" }\end{array}$ & $\begin{array}{l}\text { Chesbrough } \\
(2006, \text { p. } 1)\end{array}$ \\
\hline $\begin{array}{l}\text { Open literature } \\
\text { review [open } \\
\text { research] }\end{array}$ & $\begin{array}{l}\text { "...uses a social networking space to aggregate and collectively } \\
\text { discuss an evolving body of literature around a set of core } \\
\text { research questions." }\end{array}$ & $\begin{array}{l}\text { Conole \& } \\
\text { Alevizou }(2010, \\
\text { p. } 6)\end{array}$ \\
\hline $\begin{array}{l}\text { Open notebook } \\
\text { science }\end{array}$ & $\begin{array}{l}\text { "a form of Open Science where the laboratory notebook is made } \\
\text { public in as close to real time as possible" }\end{array}$ & $\begin{array}{l}\text { Bradley, Owens, } \\
\text { \& Williams } \\
(2008)\end{array}$ \\
\hline $\begin{array}{l}\text { Open peer } \\
\text { review }\end{array}$ & $\begin{array}{l}\text { "the opposite of double blind, in which authors' and reviewers' } \\
\text { identities are both known to each other (and sometimes publicly } \\
\text { disclosed), but... also used to describe other approaches, such as } \\
\text { where the reviewers remain anonymous but their reports are } \\
\text { published." }\end{array}$ & $\begin{array}{l}\text { Ware }(2011, p . \\
25)\end{array}$ \\
\hline Open science & $\begin{array}{l}\text { "making methodologies, data and results available on the Internet, } \\
\text { through transparent working practices" }\end{array}$ & $\begin{array}{l}\text { Lyon }(2009, p . \\
6)\end{array}$ \\
\hline Open source & $\begin{array}{l}\text { "...the practice that gives free access in production and } \\
\text { development to the source material for an end product; in most } \\
\text { cases, one is dealing with software." }\end{array}$ & $\begin{array}{l}\text { Keller \& } \\
\text { Mossink (2008, } \\
\text { p. 9) }\end{array}$ \\
\hline Open systems & $\begin{array}{l}\text { "...conform to internationally agreed standards defining computing } \\
\text { environments that allow users to develop, run and interconnect } \\
\text { applications and the hardware they run on, from whatever source, } \\
\text { without significant conversion costs" }\end{array}$ & $\begin{array}{l}\text { Bryant (1995, p. } \\
\text { 32) }\end{array}$ \\
\hline
\end{tabular}

Table 1. Sample Definitions of Open Concepts

Open activities in the HER arena are evolving in a complex, pluralist context, where multiple definitions prevail with varying levels of consistency. Several scholars have identified synergies between the different open approaches, but much of the discussion and development of policy and practice has taken place in specialist communities of interest, proceeding along parallel tracks, rather than across domains, in a coherent effort. An important contribution here is the crafting and promotion by e-InfraNet 
(2013, p. 12) of a simple, overarching definition of Open, which builds on a definition promulgated by CETIS (the former JISC-funded Centre for Educational Technology and Interoperability Standards):

"Open means ensuring that there is little or no barrier to access for anyone who can, or wants to, contribute to a particular development or use its output"

Significantly, openness here not only covers use of content, but also includes "contribution" to an activity. The policy document explicates the key concepts:

- "little or no barrier to access" means there are little or no technological, organisational, financial, legal, or even cultural restrictions to access. It also implies that access remains possible over time.

- "for anyone who can, or wants to" means whether (s)he is a regular participant in the research \& higher education system or not, and whether (s)he actually contributes/(re)uses or not.

- "contribute to a particular development or use its output" means that "little or no barrier to access" extends to "little or no barrier to participate in development and/or use the results of that development". It requires that outputs are available in their entirety (full text, complete data, source code and so on), in formats that allow processing by humans and machines; that this remain the case over time; and that access, participation and (re)use can be immediate. It also requires that full documentation is available to enable understanding of what has been made open, to allow for appropriate (re)use" (e-InfraNet, 2013, p. 12).

This is a pragmatic and wide-ranging definition, which intentionally creates opportunity for policy discussion and development. However, it immediately raises policy-based questions, particularly around levels of openness on the Gratis-Libre spectrum, already seen in relation to text mining, which may also apply more widely. It also raises a key question around the extent to which policymakers wish to take into account the development of meta-tools (including supporting documentation and metadata) that enable the reuse of Open materials, something which is inevitably resource-hungry.

\section{A Typology of Open}

Based on this broad definition, and building on the framework elaborated by e-InfraNet (2013), we propose a high-level typology, which divides the range of open approaches or domains identified in the literature and practice into three main types of openness:

- Open Content

- Open Process

- Open Infrastructure.

Table 2 presents our typology, which augments the domains covered by e-InfraNet (2013, p. 11) by adding open bibliography, open educational practices, and open systems.

\begin{tabular}{ll}
\hline Open Type & Open Domain \\
\hline Open Content & Open access to research publications (OA) \\
& Open data \\
& Open educational resources (OER, including open courseware) \\
& Open bibliography (also known as open metadata) \\
& Open source software (OSS) \\
Open development (also known as open development method, ODM) & Open educational practices (OEP) \\
Open Process & Open peer review \\
& Open science/open research \\
Open innovation & Open standards \\
Open Infrastructure & Open systems \\
\hline
\end{tabular}

Table 2. Open Typology

The key motivation associated with the Open Content domains is making content of various sorts freely accessible and available for reuse. Such content might include publications, theses and dissertations, datasets, learning objects, metadata, or computer code; Suber (2012, pp. 98-99) provides additional examples. The Open Process domains all aim to carry out academic or business processes in the public arena. Whilst they expose content, the primary purpose of this content is contributing to 
process, rather than being product. Open Infrastructure aims to produce an interoperable technical environment supporting the work of the HER community.

Figure 1 provides a high-level model of the open types indicating how they relate to each other.

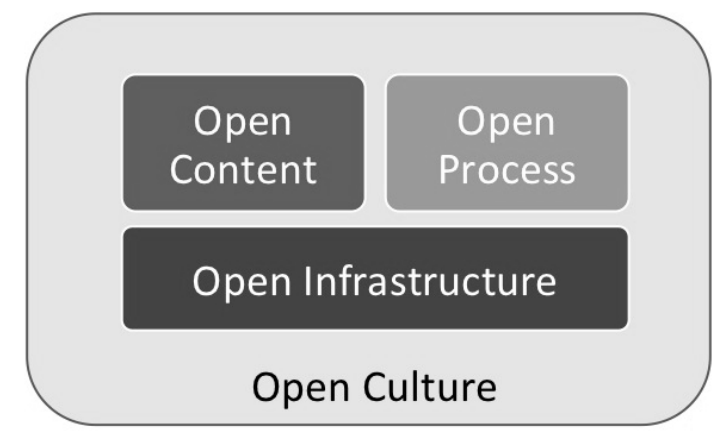

Figure 1. High-Level Open Typology

The typology as a whole has correspondences with parts of the P2P Foundation framework, although the latter is designed to inform a wider political and social agenda and takes a cross-sectoral perspective covering a large set of issues outside HER (e.g., Open Government and Open Business). The P2P framework includes (amongst others) the types "Products of Openness", "Practices of Openness", and "Infrastructures of Openness" (Good \& Bauwens, 2010; Tkacz, 2012, pp. 395, 396), which broadly correspond to Open Content, Open Process, and Open Infrastructure as outlined in the HER context.

\section{Elaborating the Open Typology}

Relationships between the different Open types are a key conceptual and policy issue. e-InfraNet (2013) proposes a particular view of their development:

"The availability of and access to e-infrastructures and content are necessary conditions for efficiency and effectiveness in modern research and higher education. For sustained and sustainable development and innovation - both within and outside research and higher education - open participatory and collaborative approaches are also required. As the availability of and access to content and infrastructural resources increases, the need for and use of 'open processes' becomes more evident. Where 'open content' is used and produced in 'open processes' within an open infrastructural setting, a culture of 'openness' gradually emerges" (eInfraNet, 2013, p. 13).

This hypothesis lays out a possible set of relationships between the Open types as they develop, and reinforces the case for Open becoming a coherent modus operandi for HER, as e-InfraNet (2013, $p$. 53) recommends. It takes as its model OSS-related development and products, where the open development process is instrumental in producing OSS content. Its advocates expect OEP and OER to have a similar process-content relationship in future (Ehlers, 2011); thus, following the huge success of OCW, MIT launched a new initiative to

"share not just the content that MIT uses in teaching - the original OCW model - but also explicit information on how we teach at MIT ...pedagogical statements from and interviews with participating faculty, links to exemplary teaching practices, showcases of educational innovations, and other framing information that places the content shared in context of our teaching philosophies" (Abelson, Miyagawa, \& Yue, 2012, p. 9).

Many MOOCs further develop the process-content relationship in the educational field by delivering openness not merely of educational content, and possibly its production, but also opening up the process of its consumption through the "connectivist" approach of online learner interaction during learning process (Cooper \& Sahami, 2013; de Waard et al., 2011; Liyanagunawardena, Adams, \& Williams, 2013).

Such ways of working could increasingly become mainstream for a range of activities within the HER community, though this would involve major cultural change, as recognized by e-Infranet (2013, pp. 
$12,40)$ in explicitly presenting Open as "Content, Process, Infrastructure and Culture", and emphasizing its "deep impacts" at different cultural levels: global, national, political, organizational, and personal.

The relationship between Open movements and culture is complex. Open requires cultural change, but also is likely to generate change. While wide dissemination is currently assumed for research publications and standards, mainstream practices in other areas typically operate on quite different assumptions; for example, peer review is normally confidential. The relationships between different Open types and their constituent domains are also complex. While conceivable that OSS as a product could be developed in a closed environment, ODM is the naturally preferred development method for OSS, so there is an instrumental relationship between them. However, in other cases an instrumental relationship between Open Process and Open Content is less clear: open science as a process and production of OA content are not necessarily linked; OA does not necessitate open science, nor vice versa. Nevertheless, overall (cause and effect), this amounts to very significant levels of change, involving the development of a radically different set of cultural norms in HER.

There are major challenges here for policymakers wishing to shape Open initiatives. First, to develop a rationale and priorities for investment, they must understand the importance and state of the different Open types and domains and their relationships. Whilst emphasizing the interconnectedness of the different Opens and the need for coordinated policy development, e-InfraNet (2013) recommends acceleration with Open Content and Open Infrastructure domains, which are arguably more mature than most Open Process domains, since barriers to wide implementation are likely to be lower; it suggests more experimentation is needed in most Open Process areas to inform further policy development.

Secondly, to bring Open approaches into the mainstream, policymakers need to facilitate cultural change. Policymakers cannot themselves effect such change, but they can incentivize behaviors likely to encourage change in academic practices and culture, albeit gradually. One key aspect is how research and scholars are evaluated or assessed, which has traditionally concentrated on published papers in high-impact journals. Andersen (2010, p. 43) suggests that "participation in open digital activities...should count toward tenure and promotion", and e-InfraNet (2013, p. 51) similarly argues

"a broader set of criteria that focus on the contribution to the advancement of knowledge. Such a contribution can be made in many different ways: by publishing an article, but also by educating students, by communicating about research questions in forums and blogs, by making datasets available, by cooperating in 'open' projects to name but a few examples."

Using these insights into relationships between phenomena of interest in the open environment, we offer a provisional model of Open, which depicts the types of Open and their interactions in an evolving open culture. Figure 2 displays our relational model of openness, showing potent reciprocal influences of Open types and Open culture on each other in a context of policy stimulus and support.

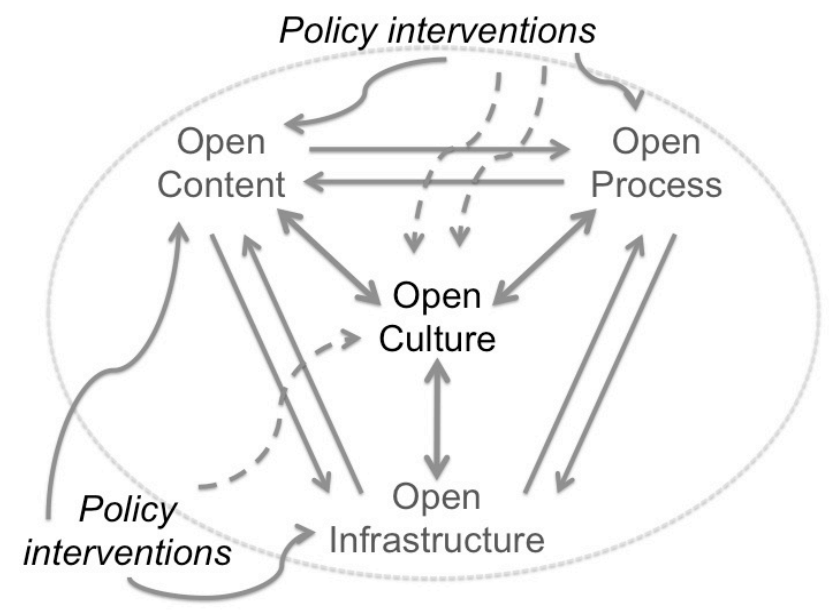

Figure 2. An Evolving Model of Open

\section{Open Convergence and Coherence}

The different Open domains have developed through a wide range of different initiatives managed at various levels: by institutions, consortia, national agencies, foundations and international bodies. Institutions such as MIT have led the OER agenda, launching OCW in 2001 to make all its online learning 
materials freely available, and expanding this in 2012 into edX, a consortium of major US universities committed to OER; the related OCW Consortium began in the US, and now has members worldwide (Peters, 2010; Yuan \& Powell, 2013). Developments in OER are mirrored in other Open domains. In some cases, national bodies, such as JISC (UK) and SURF (Netherlands), sponsored programs to promote Open approaches, particularly around OA, and more recently open data and OER (Procter, Halfpenny, \& Voss, 2012; Tedd, 2009; van der Kuil \& Feijen, 2004); e-InfraNet (2012) identified 48 examples in ten European countries. The European Commission has also sponsored European-wide programs, particularly linked to Open Content and Open Infrastructure developments, including DRIVER and DRIVER2, augmented by OpenAIRE, to encourage adoption of repository technology, and projects associated with the GÉANT network promoting interoperability with national networks (Dijk \& Van Meel, 2010; Lossau \& Peters, 2008). International organizations, such as OKF, have also contributed to Open agenda; sometimes Open approaches in HER have been linked to wider political or social movements, such as the P2P Foundation campaigning for greater openness in various ways (Peters, 2010).

Such initiatives have normally been pursued by different communities of practice, often with little or no explicit connection between them. For example, OA has been promoted by various stakeholders, including funders, librarians, and researchers in particular disciplines; whereas OER has typically been promoted by learning technologists and educationalists. The policy-based and practitioner literature on the different Open domains has seldom interacted in a meaningful way. Motivations for the different domains are typically articulated only in relation to their specific environments, amounting to

"a patchwork development of multiple open approaches, in response to different drivers in different contexts, that vary in maturity; there is not yet an 'Open' Agenda as such" (e-InfraNet, 2013, p. 7).

The apparent lack of convergence and coordination raises critical questions:

- Can the various Open domains form a single coherent policy agenda?

- More fundamentally, can the different Open domains legitimately be considered a single set of interrelated developments; or are they essentially separate initiatives, without any meaningful connections?

Willinsky (2005) provides a framework for considering the coherence of the different Open domains. His focus is open source, open access, and open science, whose fragmentation he notes, while also observing a natural "convergence" of the different domains, albeit often "unacknowledged", and largely "unrealized." His nuanced argument works on three levels:

1. The different Open domains have a shared "commitment"

2. They are governed by a set of common "economic principles"

3. The domains have shared characteristics (derived from 1 and 2).

To which we add,

4. The de facto interconnectedness between the Open domains is continuing to develop.

The different Opens are founded on a shared "commitment to the unrestricted exchange of information and ideas" (Willinsky, 2005). This fundamental tenet of Open approaches creates an obvious, but nonetheless important, level of coherence across all Open domains; it allows academic inquiry and creativity to flourish, and is also fundamental to the functioning of democratic systems. This wider societal argument, often articulated around concepts of "transparency", underpins many cases for greater openness, and is often deployed by policymakers, particularly in relation to Open Content. For example, current UK government support for $\mathrm{OA}$ and related strengthening of $\mathrm{OA}$ mandates by government research sponsors are often expressed in terms of transparency (Jha, 2011; RCUK, 2013). The "transparency" argument for Open Content can also be applied to Open Process: for example, open peer review has the potential advantage of making the quality control process at the center of scholarly communication more transparent. The immaturity of many Open Process domains (such as OEP and open science) means it is unclear exactly how this might play out. Nevertheless, the transparency argument remains important, and may itself be sufficient justification for a coordinated policy approach.

The Open domains also share three broad "economic principles", based on:

1. the efficacy of free software and research;

2. the reputation-building afforded by public access and patronage; and,

3. the emergence of a free-or-subscribe access model (Willinsky, 2005).

The first principle discusses the notion of "free" knowledge and resources, "free" here primarily referring to openness and allowing unrestricted reuse (e.g., Libre OA), revealing how information and knowledge resources are especially conducive to being managed as a "common-pool resource" (Hess \& Ostrom, 2007), because they are nonsubtractive and hence nondepletable (Corrall, 2000). Indeed, 
information resources are structurally abundant, reflected in their tendency to generate more information (exemplified in HER by the cumulative nature of scholarly knowledge), and their characteristic of "gaining value when shared or (re)used" (Corrall, 2000, p. 189) is a powerful argument for sharing, particularly in the digital environment, where use of knowledge objects is also nonrivalrous (Hess \& Ostrum, 2007; Wiley, 2010).

The second principle describes the "economics of patronage", drawing on David's $(1998,2004)$ comparison of the "open science" movement of the 17th and 18th centuries, usually funded by wealthy patrons, with "today's public patronage of research and scholarship." Willinsky (2005) illustrates how such funding supports scholarly behaviors that promote openness, drawing detailed analogies between scholarly inquiry and OSS, demonstrating a convergence of characteristics:

"Entire fields of inquiry emerge, as one article builds on another, sometimes by critique and refutation, and sometimes by replication and extension ... the research literature, as a whole, acting like an operating system that enables others to run new programs of research and to contribute, in turn, to the learning of others. Scholars carefully document their research methods, data sources, and references in ways that enable others to run the same experiment and consult the same resources ... The research article is part of a larger, very complex code on which other researchers build, debug, and extend, always with the intent of turning it back to the research community."

The argument here could apply more widely to other academic outputs, and possibly processes; research data and bibliographic information, for example, fit within this academic "operating system." Willinsky (2005) also identifies similarities in the motivations of software engineers contributing code and researchers augmenting the literature, with intellectual curiosity and the creative impulse essentially driving both groups, along with the peer recognition that characterizes the academic value system of "cooperative rivalries" (David, 1998, p. 17), or "competitive sharing" (Pinfield, 2012, p. 53). Prior contributions to the shared knowledge base create competitive advantage in the HER "economy of recognition" that potentially extends to the other open domains.

The third principle is the "free-or-subscribe model for accessing intellectual properties and public goods" that enables an "alternative economy" to coexist with commercial operations. Willinsky (2005) concentrates on entrepreneurs creating fee-based support services around free software, and does not cover the full spectrum of economic models in publishing, where OA and journal subscriptions can operate together or separately; nor does he discuss other value added services offered by publishers. The mixed economy principle is valid across the open domains, and open movements are already generating commercial opportunities, a notable example being the 2012 launch by Thomson Reuters of Data Citation Index, a priced product enabling discovery of (open) research datasets (Torres-Salinas, Martin-Martin, \& Fuente-Gutiérrez, 2013).

This framework deepens our understanding of the ethical commitment and economic principles shared by the different open domains, but also reveals and illuminates other common characteristics, particularly motivational drivers (intellectual curiosity, reputation building, competitive sharing), creating conditions for viewing the Opens as a single coherent phenomenon.

While the strength of the links between domains varies, their evident connectedness supports the case for policy coordination, a case which is reinforced by explicit manifestations of interconnectedness across Open domains. For example, OA services, such as institutional repositories, commonly deploy OSS products, including D-Space and ePrints (Mittal \& Mahesh, 2008; Pinfield et al., in press; Tedd, 2009). OA publication of research datasets alongside or embedded (interactively) in related journal articles, enabling validation of results (Rzepa, 2011; Shotton, 2012), is another manifestation of interconnectedness. Furthermore, for OERs and MOOCs to achieve their full potential they often require other complementary Opens, including open textbooks and research outputs. The Association of Research Libraries (ARL) therefore urges MOOC providers to "Set the Default to Open" for both course content and reading material (Butler, 2012, p. 14). e-InfraNet (2013, p. 48) articulates the interconnectedness of Open types as a general principle:

"if content is open, the means with which to access and process it - manually and/or through machine processing - needs to be open as well."

DRIVER is a European example promoting open infrastructure, processes and content together at a practical level (Lossau \& Peters, 2008). 


\section{Benefits of Open}

Drawing on e-InfraNet (2013), Read (2011), and other sources, we find six significant potential benefits, shared by the open domains, which offer important advantages for inquiry, pedagogy, and society, and which support the case for a unified policy agenda. While the evidence base is incomplete (reflecting the immaturity of developments), we suggest the six dimensions of Open advantage serve as a framework for monitoring activity, recording progress, and reviewing policy.

\subsection{Visibility and impact}

A growing body of evidence shows that OA increases usage and creates "citation advantage" for researchers (Swan, 2010; Wagner, 2010; Xia \& Nakanishi, 2012), though negative effects have also been reported for humanities scholars (Xu, Liu, \& Fang, 2011). Davis (2011, p. 2133) argues that the biggest potential benefit is "outside the core research community" (to those who consume, but do not contribute to the literature), confirmed by the UK public and voluntary sectors (Beddoes, Brodie, Clark, \& Hoong Sin, 2012; Look \& Marsh, 2012). Studies covering Australia, Denmark, Germany, the Netherlands, UK and US have identified wider social and economic benefits (Houghton, 2006; 2009; Houghton \& Sheehan, 2009; Houghton, Dugall, Bernius, \& Krönung, 2012; Houghton, Rasmussen, \& Sheehan, 2010), and individual case studies showing commercial impact also exist (KE, 2011). Institutions engaging with OER have similarly gained visibility and impact, notably MIT, whose material has attracted massive usage worldwide and reached learners in less developed countries (Atkins et al., 2007). The evidence for other domains is limited, although a citation advantage for papers linking to open data has been found (Dorch, 2012; Henneken \& Accomazzi, 2012; Piwowar, Day, \& Fridsma, 2007).

\subsection{Reuse}

The ability to reuse, reanalyze, recombine, and redistribute open material has transformed scientific practice, with retrievals of data from archives increasingly outnumbering data deposits; working on existing data is especially beneficial for large-scale and high-cost projects, such as the human genome and the Hubble telescope, or any endeavors where compiling data is labor-intensive (Ascoli, 2007; Beagrie, 2006; IHGSC, 2004). Reusing large corpora of scholarly articles for text mining is established practice in the biomedical field (Zweigenbaum, Demner-Fushman, Yu, \& Cohen, 2007), but evidence suggests such techniques are applicable across many more disciplines (Delen \& Crossland, 2008), and there is "clear potential for significant productivity gains" and improved research quality in the HER sector, and also wider economic and societal benefits (McDonald \& Kelly, 2012, p. 4). Despite the availability and recognized benefits of OER (e.g., quality enhancement, cost reduction), there is conflicting evidence on the level of reuse by teachers and learners in higher education practice (Hodgkinson-Williams, 2010; OPAL, 2011; White \& Manton, 2011).

\subsection{Innovation and agility}

The removal of barriers to free flow of information enabled by Open Content and Open Infrastructure promotes innovation in HER and beyond. Evidence here is limited, but includes case studies, such as the ATLAS project at CERN, whose innovative use of social media is enabled by OA material (Doyle, 2011). The Open Educational Quality Initiative also found substantial evidence that "Using OER leads to institutional innovations" (OPAL, 2011, p. 69), and there are also examples where OSS has delivered timely software solutions, improving systems and processes (University of Oxford, 2010), and demonstrating institutional agility.

\subsection{Cost-effectiveness}

e-InfraNet (2003, p. 16) notes that openness enables "efficient use of expensive resources, shared approaches, reduce duplication of effort and can save time", citing large-scale Open Infrastructure initiatives as a prime example. OER and OA can also improve the cost-effectiveness of teaching, learning, and research; for example, by using free reusable learning objects (RLOs) in course design (Christiansen \& Anderson, 2004), adopting open textbooks (Bliss, Hilton, Wiley, \& Thanos, 2013), and moving from subscription-based journals to Green or Gold OA literature (Jubb, Cook, Hulls, Jones, \& Ware, 2011).

\subsection{Quality enhancement}

Increasing visibility of content and inviting input from others creates a "virtuous circle ...improving quality of learning, research, software and administration" (e-Infranet, 2013, p. 14). One-third of MIT OCW faculty report the process "improves their course materials" (d'Oliveira \& Lerman, 2009), while citizen science 
and volunteer computing are helping to solve problems previously beyond the reach of research teams (Lyon, 2009; Royal Society, 2012).

\subsection{Reputation and trust}

Availability of Open Content and more open conduct of research can promote institutional expertise to industry and the media, enhance confidence in HER institutions as public bodies, and mitigate the risks of unmanaged exposure of data or other materials. The value of OER for marketing and branding in student recruitment is widely recognized (Yuan \& Powell, 2013): one-third of incoming students cited MIT OCW as "a significant influence in their choice of school"; and one-third of participating faculty reported publication of their course materials had "improved their professional standing in their field" (d'Oliveira \& Lerman, 2009).

\section{Limits of Open}

Understanding the limits of Open domains will challenge policymakers. Most Open approaches arguably have "natural" limits, which need to be identified and tested. For example, OA to research literature is typically defined in terms of peer-reviewed journals (BOAI, 2002), which are royalty free, unlike conventionally-published monographs (though there have been experiments with OA e-monographs, which again are characteristically royalty free). OA thus assumes authors are not paid directly for their work, so it is reasonable to define its natural limit as the royalty-free research literature, rather than the research literature as a whole, which then has implications for policy development in designing institutional or funder OA "mandates."

There are important reasonable limits to openness for research data, such as publishing findings before research data are shared, maintaining commercial confidentiality for industry sponsored research, and respecting the privacy and sensitivity of research subjects; research ethics committees/institutional review boards often restrict secondary use of data related to human participants - access to datasets may be limited to qualified researchers, or denied pending inspection for quality (Eschenfelder \& Johnson, 2012; Smith, 2011). Data then may have to be anonymized before sharing and processed for re-use, limiting what can be shared and when. Policy developers need to establish clear criteria for selecting data to be shared, protocols for the timing of sharing, and enabling processes and systems.

Selectivity is also likely to prevail in relation to OER. Unlike MIT, most institutions do not choose to share everything, to protect existing business models of fee-based courses. Policy therefore must focus on developing criteria for sharing. We need to recognize that Open resources will continue to exist in a mixed environment. In particular, while software produced within the community to support research and teaching could become open by default, HER institutions will likely continue to deploy both opensource and commercial solutions to support both academic and administrative functions.

Notions of "selectivity" and "mixed economy" are controversial and may be used to perpetuate fundamentally non-Open approaches; for example, publisher embargoes on self-archiving research papers may delay OA beyond their useful life. UK research funders are challenging embargoes of more than six months for STEM disciplines or 12 months for arts, humanities and social sciences (RCUK, 2013), but their policy intervention has divided stakeholder opinion, with some research universities arguing for a much longer embargo for non-STEM subjects (1994 Group, 2013).

Another limitation on achieving real openness is the extra effort required (actual or perceived) in comparison with existing practices. Future policy debate is likely to focus on the limits of Open and their implications, while experimental work will continue to challenge the positioning of community-accepted or policy-sanctioned boundaries. Further investigation is required here, from both research and policy perspectives.

\section{Policy Implications}

Our analysis has highlighted the pluralities and complexities of the open landscape, including factors policymakers should consider when designing interventions - such as the levels, benefits, and limits of openness, as well as the development paths, maturity stages, and interrelationships of the different domains, including their potential convergent momentums, and relevant cultural dimensions. Other specific challenges to openness are discussed in the literature (e.g., intellectual property rights, business models, sustainability), though generally in relation to particular domains, and we suggest that here too the HER community needs cross-domain work that examines issues holistically, such as the Dutch study that produced licensing recommendations for sharing both educational and research materials (Keller \& Mossink, 2008). A more holistic approach is likely to highlight further challenges that can be most effectively addressed through policy interventions which take into account the multi-dimensional nature of 
the problem. One example of this is the extent that Open approaches require faculty (and others) to carry out additional work. Sharing of research data, for example, often requires extensive processing of datasets and production of metadata to enable reuse. Opening up educational resources similarly requires additional work to create contexts for wider use and reuse. A holistic approach to comprehending and addressing these challenges is more likely to result in workable policy solutions.

A related issue already identified but not fully examined is the multiplicity of stakeholder groups across the open domains, including their particular roles in open initiatives, and the impacts on them. We suggest again that potential synergies across the domains could be better exploited by viewing Open holistically, for example transferring lessons learned and skills developed from one open domain to another. Also, as e-InfraNet (2013, p. 49) notes, a "fragmented perspective" may not only slow down development, but may "adversely affect...the entire system." Supra-institutional agencies (national and international organizations) can influence behaviors here by funding programs that require cross-domain rather than single-domain open developments.

Policy initiatives ultimately must focus on developments at the institutional level, where scholarly activities with open potential take place. Emerging evidence suggests openness can enhance performance in relation to HER missions of teaching, learning, research, and enterprise/knowledge transfer, with benefits for individuals, communities, economy and society. Our study suggests institutions will gain additional advantage through integrated (not separate) policies that exploit the convergence of open domains and recognize general common benefits, while observing particular domain-specific limits (e.g., adjusting academic reward systems to encourage behavior that will increase openness in both research and teaching).

\section{Conclusion}

Taken together, the ethical commitment, economic principles, common characteristics, de facto interconnectedness, and potential benefits shared by the different domains make the case for the convergence and coherence of Open initiatives. More work is needed to test the arguments in some areas and to strengthen the evidence base in others. The frameworks presented here can be used to inform policy discussion and future studies of Open.

\section{References}

1994 Group (2013). Open Access. 1994 Group: Extend the embargo. Times Higher Education, April 4, 2013. Retrieved November 9, 2013, from http://www.timeshighereducation.co.uk/news/news-inbrief-4-april-2013/2002942.article

Abelson, H., Miyagawa, S., \& Yue, D. (2012). MIT's ongoing commitment to OpenCourseWare. MIT Faculty Newsletter, XXIV(4), 8-9. Retrieved November 9, 2013, from http://web.mit.edu/fnl/volume/244/fnl244.pdf

Andersen, M. H. (2010). The open faculty - To share or not to share: Is that the question? EDUCAUSE Review, 45(4), 40-49. Retrieved November 9, 2013, from http://net.educause.edu/ir/library/pdf/ERM1043.pdf

Anderson, P. (2009). Avoiding abandon-ware: getting to grips with the open development method. Briefing Notes. OSS Watch. Retrieved November 9, 2013, from http://www.osswatch.ac.uk/resources/odm

ANSI (2005). Current attempts to change established definition of "open" standards. Critical Issue Papers. American National Standards Institute. Retrieved November 9, 2013, from http://publicaa.ansi.org/sites/apdl/Documents/Standards\%20Activities/Critical\%20lssues/OpenStds.pdf

Ascoli, G. (2007). Successes and rewards in sharing digital reconstructions of neuronal morphology. Neuroinformatics, 5(2), 154-160.

Atkins, D. E., Brown, J. S., \& Hammond, A. L. (2007). A review of the open educational resources (OER) movement: Achievements, challenges, and new opportunities. Menlo Park, CA: William and Flora Hewlett Foundation. Retrieved November 9, 2013, from http://www.hewlett.org/uploads/files/Hewlett_OER_report.pdf

Beddoes, D., Brodie, E., Clarke, R., \& Hoong Sin, C. (2012). Benefits of open access to scholarly research for voluntary and charitable sector organisations: A research report to JISC from the Office for Public Management and the National Council of Voluntary Organisations. Bristol: JISC. Retrieved November 9, 2013, from http://repository.jisc.ac.uk/576/1/JISC_open_access_and_VCS_report-FINAL.pdf 
Bliss, T. J., Hilton, J., Wiley, D., \& Thanos, K. (2013). The cost and quality of open textbooks: Perceptions of community college faculty and students. First Monday, 18(1). doi:10.5210/fm.v.18i1.3972

BOAI (2002). Read the Budapest Open Access Initiative. Retrieved November 9, 2013, from http://www.budapestopenaccessinitiative.org/read

Boyer, E. L. (1990). Scholarship reconsidered: Priorities of the professoriate. San Francisco, CA: Jossey Bass. Retrieved November 9, 2013, from http://www.umces.edu/sites/default/files/al/pdfs/BoyerScholarshipReconsidered.pdf

Bradley, J.-C., Owens, K., \& Williams, A. (2008). Chemistry crowdsourcing and open notebook science. Nature Precedings, January 9. Retrieved November 9, from, http://precedings.nature.com/documents/1505/version/1/files/npre20081505-1.pdf

Bryant, J. R. (1995). Open systems. International Journal of Bio-Medical Computing, 39(1), 31-34.

Butler, B. (2012). Massive open online courses: Legal and policy issues for research libraries. Issue Brief. Washington, DC: Association of Research Libraries. Retrieved November 9, 2013, from http://www.arl.org/storage/documents/publications/issuebrief-mooc-22oct12.pdf

Cerri, D., \& Fuggetta, A. (2007). Open standards, open formats, and open source. Journal of Systems and Software, 80(11), 1930-1937. doi:10.1016/j.jss.2007.01.048

Chesbrough, H. (2006). Open innovation: A new paradigm for understanding industrial innovation. In $\mathrm{H}$. Chesbrough, W. Vanhaverbeke \& J. West, J. (Eds.). Open innovation: Researching a new paradigm (pp. 1-12). Oxford: Oxford University Press.

Christiansen, J.-A., \& Anderson, T. (2004). Feasibility of course development based on learning objects: Research analysis of three case studies. International Journal of Instructional Technology \& Distance Learning, 1(3), 21-38. Retrieved November 9, 2013, from http://www.itdl.org/Journal/Mar_04/index.htm

Clark, J. (2013). Text mining and scholarly publishing. Publishing Research Consortium. Retrieved November 9, 2013, from http://www.publishingresearch.net/documents/PRCTextMiningandScholarlyPublishinFeb2013.pdf

Conole, G., \& Alevizou, P. (2010). A literature review of the use of Web 2.0 tools in higher education: A report commissioned by the Higher Education Academy. Milton Keynes, UK: The Open University. Retrieved November 9, 2013, from http://www.heacademy.ac.uk/assets/EvidenceNEt/Conole_Alevizou_2010.pdf

Cooper, S., \& Sahami, M. (2013). Reflections on Stanford's MOŌCs. Communications of the ACM, 56(2), 28-30. doi:10.1145/2408776.2408787

Corrall, S. (2000). Strategic management of information services: A planning handbook. London: Aslib/IMI.

d'Oliveira, C., \& Lerman, S. (2009). OpenCourseWare: Working through financial challenges. MIT Faculty Newsletter, XXII(1), 14-15. Retrieved November 9, 2013, from http://web.mit.edu/fnl/volume/221/fnl221.pdf

David, P. A. (1998). Common agency contracting and the emergence of "open science" institutions. American Economic Review, 88(2), 15-21.

David, P. A. (2004). Understanding the emergence of 'open science' institutions: Functionalist economics in historical context. Industrial and Corporate Change, 13(4), 571-589. doi:10.1093/icc/dth023

Davis, P. M. (2011). Open access, readership, citations: A randomized controlled trial of scientific journal publishing. The FASEB Journal, 25(7), 2129-2134. Retrieved November 9, 2013, from http://www.fasebj.org/content/25/7/2129.full.pdf

de Waard, I., Abajian, S., Gallagher, M. S., Hogue, R., Keskin, N., Koutropoulos, A., \& Rodriguez, O. C. (2011). Using mLearning and MOOCs to understand chaos, emergence, and complexity in education. International Review of Research in Open and Distance Learning, 12(7), 94-115. Retrieved November 9, 2013, from http://www.irrodl.org/index.php/irrodl/article/view/1046

Dijk, E., \& Van Meel, M. (2010). Using a CRIS for e-infrastructure: e-infrastructure for scholarly publications. Data Science Journal, 9(0), p.CRIS59. Retrieved November 9, 2013, from https://www.jstage.jst.go.jp/article/dsj/9/0/9_CRIS8/_pdf

Doyle, T. (2011). Using open access to collaborate on the largest experiment in the world - and inspire the next generation of particle physicists. Copenhagen: Knowledge Exchange. Retrieved November 9, 2013, from http://www.oastories.org/2011/09/ukworldwide-researcher-professor-tonydoyle-cern-atlas/

e-InfraNet (2012). Overview of the National Programmes in Europe - Open. European Network for coordination of policies and programmes on e-infrastructures (e-InfraNet Project). Retrieved 
November 9, 2013, from http://e-infranet.eu/output/overview-of-the-national-programmes-ineurope-open/

e-InfraNet (2013). e-InfraNet: 'Open' as the default modus operandi for research and higher education. European Network for co-ordination of policies and programmes on e-infrastructures (e-InfraNet Project). Retrieved November 9, 2013, from http://e-infranet.eu/output/e-infranet-open-as-thedefault-modus-operandi-for-research-and-higher-education/

Ehlers, U. D. (2011). Extending the territory: From open educational resources to open educational practices. Journal of Open, Flexible and Distance Learning, 15(2), 1-10. Retrieved November 9, 2013, from http://journals.akoaotearoa.ac.nz/index.php/JOFDL/article/viewFile/64/46

Esposito, A. (2013). Neither digital or open, just researchers: Views on digital/open scholarship practices in an Italian university. First Monday, 18(1). doi:10.5210/fm.v18i1.388

Ford, E. (2013). Defining and characterizing open peer review: A review of the literature. Journal of Scholarly Publishing, 44(4), 311-326. doi:10.3138/jsp.44-4-001

Garnett, F., \& Ecclesfield, N. (2011). Towards a framework for co-creating open scholarship. ALT-C 2011 Conference Proceedings: 18th International conference of the Association for Learning Technology, Leeds, UK, September 6-8, 2011. Retrieved November 9, 2013, from http://repository.alt.ac.uk/2177/1/rlt7795.pdf

Good, R., \& Bauwens, M. (2010). P2P and open infrastructures: The society of openness comes of age. Master New Media. Retrieved November 9, 2013, from http://www.masternewmedia.org/p2p-andopen-infrastructures-the-society-of-openness-comes-of-age/

Henneken, E. A., \& Accomazzi, A. (2012). Linking to data: Effect on citation rates in astronomy. In P. Ballester, D. Egret \& P. F. N. Lorente (Eds.). Astronomical Data Analysis Software and Systems XXI, Paris, France, November 6-10, 2012 (pp. 763-766). Retrieved November 9, 2013, from http://www.aspbooks.org/a/volumes/article_details/?paper_id=34778

Hess, C., \& Ostrom, E. (2007). Introduction: An overview of the knowledge commons. In C. Hess \& E. Ostrom (Eds.). Understanding knowledge as a commons: From theory to practice (pp. 3-26). Cambridge, MA: MIT Press.

Hodgkinson-Williams, C. (2010). Benefits and challenges of OER for higher education institutions. Vancouver: Commonwealth of Learning. Retrieved November 9, 2013, from http://www.col.org/SiteCollectionDocuments/OER_BenefitsChallenges_presentation.pdf

Houghton, J. (2009). Open access - what are the economic benefits? A comparison of the United Kingdom, Netherlands and Denmark. Melbourne: Victoria University. Retrieved November 9, 2013, from http://www.knowledge-exchange.info/Default.aspx?ID=316

Houghton, J., \& Sheehan, P. (2009). Estimating the potential impacts of open access to research findings. Economic Analysis and Policy, 39(1), 127-142. Retrieved November 9, 2013, from http://www.eap-journal.com/archive/v39_i1_10_-houghton.pdf

Houghton J., Dugall, B., Bernius, S., Krönung, J., \& König, W. (2012). General cost analysis for scholarly communication in Germany: Results of the "Houghton Report" for Germany. Frankfurt: Goethe University. Retrieved November 9, 2013, from http://publikationen.ub.unifrankfurt.de/frontdoor/index/index/docld/27530

Houghton, J., Rasmussen, B., \& Sheehan, P. (2010). Economic and social returns on investment in open archiving of publicly funded research outputs: Report to SPARC. Washington, DC: Scholarly Publishing \& Academic Resources Coalition. Retrieved November 9, 2013, from http://www.sparc.arl.org/sites/default/files/vufrpaa.pdf

Houghton, J., Steele, C., \& Sheehan, P. (2006). Research communication costs in Australia: Emerging opportunities and benefits: A report to the Department of Education, Science and Training. Melbourne: Victoria University, Centre for Strategic Economic Studies. Retrieved November 9 , 2013, from http://hdl.handle.net/1885/44485

Howard, J. (2012). Elsevier experiments with allowing 'text mining' of its journals. The Chronicle of Higher Education, May 6, 2012. Retrieved November 9, 2013, from http://chronicle.com/article/Hot-TypeElsevier-Experiments/131789/

liyoshi, T., \& Kumar, M. S. V. (Eds.). (2008). Opening up education: The collective advancement of education through open technology, open content, and open knowledge. Cambridge, MA: MIT Press. Retrieved November 9, 2013, from http://mitpress.mit.edu/books/opening-education

Jha, A. (2011). Results of publicly funded research will be open access - science minister. Guardian December 8, 2011. Retrieved November 9, 2013, from http://www.theguardian.com/science/2011/dec/08/publicly-funded-research-open-access 
Jones, R., MacGillivray, M., Murray-Rust, P., Pitman, J., Sefton, P., O’Steen, B., \& Waites, W. (2011). Open bibliography for science, technology, and medicine. Journal of Chemoinformatics, 3(October), 47. doi:10.1186/1758-2946-3-47

Jubb, M., Cook, J., Hulls, D., Jones, D., \& Ware, M. (2011). Costs, risks and benefits in improving access to journal articles. Learned Publishing, 24(4), 247-260. doi:10.1087/20110402

Katz, R, N, (2010). Scholars, scholarship, and the scholarly enterprise in the digital age. EDUCAUSE Review, 45(2), 44-56. Retrieved November 9, 2013, from http://net.educause.edu/ir/library/pdf/ERM1023.pdf

KE (2011). Open access success stories. Copenhagen: Knowledge Exchange. Retrieved November 9 , 2013, from http://www.oastories.org/success-stories/

Keller , P., \& Mossink, W. (2008). Reuse of material in the context of education and research. Utrecht: SURFDirect. Retrieved November 9, 2013, from http://www.surf.nl/en/publicaties/pages/reuseofmaterial.aspx

Kelly, B., Wilson, S., \& Metcalfe, R. (2007). Openness in higher education: Open source, open standards, open access. In L. Chan \& B. Martens (Eds.). ELPUB2007: Openness in Digital Publishing: Awareness, Discovery and Access - Proceedings of the 11th International Conference on Electronic Publishing, Vienna, Austria, June 13-15, 2007 (pp. 161-174). Vienna: ÖKK-Editions. Retrieved November 9, 2013, from http://elpub.scix.net/data/works/att/140_elpub2007.content.pdf

Kuchma, I. (2008). Open access, equity, and strong economy in developing and transition countries: Policy perspective. Serials Review, 34(1), 13-20. doi:10.1016/j.serrev.2007.12.004

Leeson, J., \& Mason, J. (2007). The open agenda and organisational alignment. 15th International Conference on Computers in Education, Hiroshima, Japan, November 5-9, 2007, Supplementary Proceedings, Vol. 1 (pp. 189-194).

Liyanagunawardena, T., Adams, A. A., \& Williams, S. A. (2013). MOOCs: A systematic study of the published literature 2008-2012. International Review of Research in Open and Distance Learning, 14(3), 202-227. Retrieved November 9, 2013, from http://www.irrodl.org/index.php/irrodl/article/view/1455

Look, H., \& Marsh, K. (2012). Benefits of open access to scholarly research to the public sector. A research report to JISC from Rightscom Ltd and Matrix Evidence Ltd. Bristol: JISC. Retrieved November 9, 2013, from http://repository.jisc.ac.uk/575/1/publicsector_oa_report_final_20120312.pdf

Lossau, N., \& Peters, D. (2008). DRIVER: Building a sustainable infrastructure of European scientific repositories. LIBER Quarterly, 18(3/4):,437-448. Retrieved November 9, 2013, from http://liber.library.uu.nl/index.php/lq/issue/view/462

Lyon, L. (2009). Open science at web-scale: Optimising participation and predictive potential. Consultative Report. Bristol: JISC. Retrieved November 9, 2013, from http://www.jisc.ac.uk/publications/reports/2009/opensciencerpt.aspx

McDonald, D., \& Kelly, U. (2012). The value and benefits of text mining. Bristol: JISC. Retrieved November 9, 2013, from http://www.jisc.ac.uk/publications/reports/2012/value-and-benefits-of-textmining.aspx

Mittal, R., \& Mahesh, G. (2008). Digital libraries and repositories in India: An evaluative study. Program, 42(3), 286-302. doi:10.1108/00330330810892695

OCW Consortium (n.d.). What is OpenCourseWare? OpenCourseWareConsortium. Retrieved November 9, 2013, from http://www.ocwconsortium.org/faq/what-is-open-courseware/

OPAL (2011). Beyond OER: Shifting focus to open educational practices. Essen, Germany: Open Educational Quality Initiative. Retrieved November 9, 2013, from http://duepublico.uni-duisburgessen.de/servlets/DocumentServlet?id=23933

OKF (2011). Open definition (Version 1.1). Cambridge: Open Knowledge Foundation. Retrieved November 9, 2013, from http://opendefinition.org/okd/

Pearce, N., Weller, M., Scanlon, E., \& Ashleigh, M. (2010). Digital scholarship considered: How new technologies could transform academic work. In Education, 16(1), 33-44. Retrieved November 9, 2013, from http://ineducation.ca/index.php/ineducation/article/view/44/509

Peters, M. A. (2010). Three forms of the knowledge economy: Learning, creativity and openness. British Journal of Educational Studies, 58(1), 67-88. doi:10.1080/00071000903516452

Peters, M. A., \& Roberts, P. (2012). The virtues of openness: Education, science, and scholarship in the digital age. Boulder, CO: Paradigm.

Pinfield, S. (2012). Opening up the academy: The "open" agenda, technology, and universities. EDUCAUSE Review, 47(1), 52-53. http://net.educause.edu/ir/library/pdf/ERM1217.pdf 
Pinfield, S., Salter, J., Bath, P., Hubbard, B., Millington, P., Anders, J., \& Hussain, A. (in press). Openaccess repositories worldwide, 2005-2012: Past growth, current characteristics and future possibilities. Journal of the American Society for Information Science and Technology. Retrieved November 9, 2013, from http://eprints.whiterose.ac.uk/76632

Piwowar, H. A., Day, R. S., \& Fridsma, D. B. (2007). Sharing detailed research data is associated with increased citation rate. PLOS ONE, 2(3): e308. doi:10.1371/journal.pone.0000308

Procter, R., Halfpenny, P., \& Voss, A. (2012). Research data management: Opportunities and challenges for HEls. In G. Pryor (Ed.). Managing research data (pp. 135-150). London: Facet.

Ray, D., Gulla, U., Dash, S. S., \& Gupta, M. P. (2011). A critical survey of selected government interoperability frameworks. Transforming Government: People, Process and Policy, 5(2), 114-142. doi:10.1108/17506161111131168

Read, M. (2011). Open resources: The need for integration. EDUCAUSE 2011 Annual Conference, Philadelphia, PA, October 18-21, 2011. Retrieved November 9, 2013, from http://www.educause.edu/annual-conference/2011/open-resources-need-integration

RCUK (2013). RCUK policy on open access and supporting guidance. Swindon: Research Councils UK. Retrieved November 9, 2013, from http://www.rcuk.ac.uk/documents/documents/RCUKOpenAccessPolicy.pdf

Rhoten, D., \& Powell, W. W. (2007). The frontiers of intellectual property: Expanded protection versus new models of open science. Annual Review of Law and Social Science, 3, 345-373.

Royal Society (2012). Science as an open enterprise. London: The Royal Society. Retrieved November 9 , 2013, from http://royalsociety.org/policy/projects/science-public-enterprise/report/

Rzepa, H. (2011). The past, present and future of scientific discourse. Journal of Chemoinformatics, 3(October), 46. doi:10.1186/1758-2946-3-46

Schroeder, R. (2007). e-Research infrastructures and open science: Towards a new system of knowledge production? Prometheus, 25(1), 1-17. doi:10.1080/08109020601172860

Schuwer, R., \& Mulder, F. (2009) OpenER, a Dutch initiative in Open Educational Resources, Open Learning: The Journal of Open, Distance and e-Learning, 24(1), 67-76. doi:10.1080/02680510802627852

Shotton, D. (2012). The five stars of online journal articles - a framework for article evaluation. D-Lib Magazine, 18(1/2). doi:10.1045/january2012-shotton

Smith, E. (2011). The limits of sharing: An ethical analysis of the arguments for and against the sharing of databases and material banks. Accountability in Research: Policies and Quality Assurance, (18)6, 357-381. doi:10.1080/08989621.2011.609443

Stokker, J. (2011). Open access: A widening agenda - An Australian perspective. Proceedings of the 32nd Annual IATUL Conference, Warsaw, Poland, May 29-June 2, 2011 (Paper 14). Retrieved November 9, 2013, from http://docs.lib.purdue.edu/iatul/2011/papers/14

Suber, P. (2012). Open access. Cambridge, MA: MIT Press. Retrieved November 9, 2013, from http://mitpress.mit.edu/books/open-access

Swan, A. (2010). The open access citation advantage: Studies and results to date. Technical Report. Southampton: University of Southampton, School of Electronics and Computer Science. Retrieved November 9, 2013, from http://eprints.soton.ac.uk/268516/

Tedd, L. A. (2009). Open access publishing and institutional repositories: An overview. 7th International Convention on Automation of Libraries in Education and Research, Pondicherry, India, February 25-27, 2009 (pp. 572-584). Gandhinagar, India: Information and Library Network (INFLIBNET) Centre. Retrieved November 9, 2013, from http://www.inflibnet.ac.in/caliber2009/CaliberPDF/71.pdf

Tiemann, M. (2005). An objective definition of open standards. Computer Standards \& Interfaces, 28(5), 495-507. doi:10.1016/j.csi.2004.12.003

Tkacz, N. (2012). From open source to open government: A Critique of open politics. Ephemera, 12(4), 386-405. Retrieved November 9, 2013, from http://www.ephemerajournal.org/sites/default/files/124tkacz_0.pdf

Torres-Salinas, D., Martín-Martín, A., \& Fuente-Gutiérrez, E. (2013). An introduction to the coverage of the Data Citation Index (Thomson-Reuters): Disciplines, document types and repositories. EC3 Working Papers. Granada, Spain: Evaluación de la Ciencia y la Comunicación Científica [Evaluation of Science and Scientific Communication], University of Grenada. Retrieved November 9, 2013, from http://arxiv.org/pdf/1306.6584v1.pdf

Undheim, T. A., \& Friedrich, J. (2008). The momentum of open standards: A pragmatic approach to software interoperability. European Journal of ePractice, 5, 1-13. Retrieved November 9, 2013, from http://www.epractice.eu/files/5.1.pdf 
UNESCO (2012). 2012 Paris OER declaration. World Open Educational Resources (OER) Congress, Paris, June 20-22, 2012. Paris: UNESCO. Retrieved November 9, 2013, from http://www.unesco.org/new/fileadmin/MULTIMEDIA/HQ/Cl/Cl/pdf/Events/English_Paris_OER_Decl aration.pdf

University of Oxford (2010). Customizing open source software: benefits and pitfalls. Cascade Project: Case Study 2. Bristol: JISC. Retrieved November 9, 2013, from http://www.jisc.ac.uk/media/documents/programmes/elearning/CascadeCaseStudy2.pdf

van der Kuil, A., \& Feijen, M. (2004). The dawning of DARE: A shared experience. Ariadne, 41. Retrieved November 9, 2013, from http://www.ariadne.ac.uk/issue41/vanderkuil

Wagner, A. B. (2010). Open access citation advantage: An annotated bibliography. Issues in Science and Technology Librarianship, 60. Retrieved November 9, 2013, from http://www.istl.org/10winter/article2.html

Ware, M. (2011). Peer review: Recent experience and future directions. New Review of Information Networking, 16(1), 23-53.

Weber S. (2004). The success of open source. Cambridge, MA: Harvard University Press.

Wellen, R. (2013). Open access, megajournals, and MOOCs: On the political economy of academic unbundling. SAGE Open, 3(4). doi:10.1177/2158244013507271

White, D., \& Manton, M. (2011). Open educational resources: The value of reuse in higher education. JISC-funded OER Impact Study. Oxford: University of Oxford. Retrieved November 9, 2013, from http://www.jisc.ac.uk/whatwedo/programmes/elearning/oer2/oerimpact.aspx

Whyte, A., \& Pryor, G. (2011). Open science in practice: Researcher perspectives and participation. International Journal of Digital Curation, 1(6), 199-213. doi:10.2218/ijdc.v6i1.182

Wiley, D. (2010). The open future: Openness as a catalyst for an educational transformation. EDUCAUSE Review, 45(4), 14-20. Retrieved November 9, 2013, from http://net.educause.edu/ir/library/pdf/ERM1040.pdf

Wiley, D., \& Gurrell, S. (2009). A decade of development...Open Learning: The Journal of Open, Distance and e-Learning, 24(1), 11-21. doi:10.1080/02680510802627746

Willinsky, J. (2005). The unacknowledged convergence of open source, open access and open science. First Monday, 10(8). Retrieved November 9, 2013, from http://firstmonday.org/ojs/index.php/fm/article/view/1265/1185

Xia, J., \& Nakanishi, K. (2012). Self-selection and the citation advantage of open access articles. Online Information Review, 36(1), 40-51. doi:10.1108/14684521211206953

$\mathrm{Xu}$, L., Liu, J., \& Fang, Q. (2011). Analysis on open access citation advantage: An empirical study based on Oxford open journals. iConference 2011: Proceedings of the 2011 iConference (pp. 426-432). New York: ACM. doi:10.1145/1940761.1940819

Yuan, L. \& Powell, S. (2013). MOOCs and open education: Implications for higher education. White Paper. Bolton: JISC CETIS: Centre for Educational Technology \& Interoperability Standards.

Retrieved November 9, 2013, from http://publications.cetis.ac.uk/2013/667

Zweigenbaum, P., Demner-Fushman, D., Yu, H., \& Cohen, K. B. (2007). Frontiers of biomedical text mining: Current progress. Briefings in Bioinformatics, 8(5), 358-375. doi:10.1093/bib/bbm045

\section{Table of Figures}

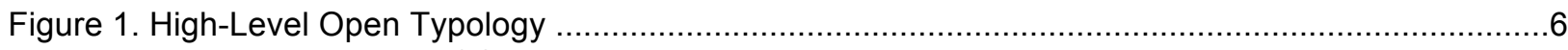

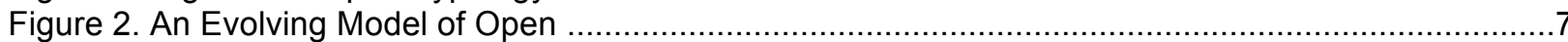

\section{Table of Tables}

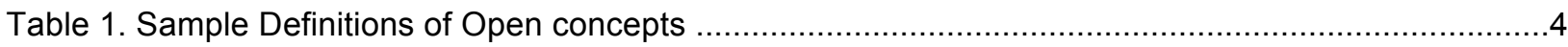

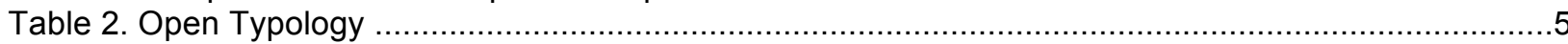

